\title{
Should participants be given a mobile phone, or use their own? Effects of Novelty vs Utility
}

Walsh, E.I, \& Brinker, J.

Due to their ubiquity, mobile telephones may herald a great opportunity for ecological momentary assessment data collection. To access samples which do not own a mobile, or do not own a mobile that supports the preferred mode of response (i.e. apps), researchers may wish to provide participants with an appropriate mobile telephone for the purposes of participation. This often involves replacing a phone already in use. This study investigated the impact of providing a mobile telephone to participants for the purposes of participating in research, comparing the response behaviour of participants using their own mobile telephone against those using one provided by the researcher. Using iPhone 3s, 179 undergraduate participants completed a six-item questionnaire, 20 times over two day via app or text message. The three experimental groups consisted of those using their own iPhone, those using their own SIM in a provided iPhone, and those using a provided SIM in a provided iPhone. Results suggest that researchers seeking to conduct self-report research using mobile phones should be aware that the choice to provide a mobile telephone to standardise participant response platforms can impact on response behaviour.

Citation: Walsh, E. I., \& Brinker, J. K. (2016). Should participants be given a mobile phone, or use their own? Effects of novelty vs utility. Telematics and Informatics, 33(1), 25-33. DOI: 10.1016/j.tele.2015.06.006

(C) 2015. This manuscript version is made available under the CC-BY-NC-ND 4.0 license http://creativecommons.org/licenses/by-nc-nd/4.0/

Acknowledgements. The authors would like to thank Dr. Janie Busby Grant for providing the iPhones used this research, and the University of Canberra for allowing us access to their undergraduate population. 


\section{Introduction}

There are an estimated 96 mobile subscriptions per 100 people globally (International telecommunication union, 2014). Mobile technology offers an unprecedented method of bidirectional communication between practitioners, clients, researchers and participants, through text-only technologies like Short Message Service (SMS) available on all mobile telephones, and mobile software (apps) and internet connectivity offered by smartphones. The past few years have seen a proliferation of physical health (see Boulos, Brewer, Karimkhani, Buller, \& Dellavalle, 2014; Joe \& Demiris, 2013; Mars, 2013) and mental health (see Aggarwal, 2012; Proudfoot, 2013; Shingleton, Richards, \& Thompson-Brenner, 2013) interventions centred around mobile technology. Researchers too are beginning to capitalize on mobile technology as a mode of self-report data collection in psychological research (see Kuntsche \& Labhart, 2013). When using mobile telephones in this way, it may be necessary to provide participants with a mobile telephone, either because they do not have one, the mobile they do have might be unsuitable for participation, or the researcher wants to standardize the research experience.

If a potential participant does not have a mobile, researchers may ask them to borrow someone else's mobile for the purposes of participation (e.g. Lagerros, Sandin, Bexelius, Litton, \& Löf, 2012), or switch to a different method of data collection (e.g. Macedo, Maher, Latimer, \& McAuley, 2012). The most common approach is to exclude participants without mobiles from data collection, either by using mobile telephone number registries for initial contact and recruitment (e.g. Bexelius, Merk, Sandin, Ekman, Nyrén, et al., 2009; Chib et al., 2012; Gold et al., 2011; Lim et al., 2010), or excluding non-mobile owners after initial contact and screening (e.g. Axén, Bergström, \& Bodin, 2013; Devine et al., 2014; Suffoletto, Kristan, Callaway, Kraemer, \& Clark, 2011). Whilst this approach is generally tenable due to 
a relatively high saturation of mobile ownership worldwide, it can be problematic with specific populations, such as adults in rural or developing areas, and children.

There are few examples where adult participants in a developed country were given the option to borrow a mobile if they did not own one, or did not wish to use their own for the purposes of participation (e.g. Berkman, Dickenson, Falk, \& Lieberman, 2011). Historically, participants in developing countries are unlikely to own mobile telephones, and so researchers have provided them one (e.g. Andreatta, Debpuur, Danquah, \& Perosky, 2011; Lori, Munro, Boyd, \& Andreatta, 2012). As global mobile penetration increases, and mobile ownership even in poorer areas is becoming more common, research with children has become the primary area where mobile telephones are given to participants. This is done by either providing a mobile directly to the child (e.g. Alfven, 2010; Bauer, de Niet, Timman, \& Kordy, 2010; de Niet et al., 2012) or to the parent or caregiver (e.g. Broderick et al., 2012; Chen, Chin, Greenberg, Johnstone, \& McGuinness, 2012; Kazi, Murtaza, Khoja, \& Ali, 2014). This approach may facilitate data collection, but purchasing mobile telephones (particularly smartphones) can be costly, and requires personal contact with the participant to hand over the mobile telephone. The cost and need to physically meet participants means lending mobile handsets may not be viable for large scale studies.

The ubiquity of mobile phones has shifted the issue from whether participants have mobile telephones to the type of mobile telephones they have. In Australia, there are 130 mobile phones per 100 citizens (ACMA, 2011), 64\% of which are smartphones (ThinkInsights, 2014). Though almost all mobile telephones support SMS, it is considerably more difficult to type an SMS response using the multi-press numeric keyboard system of a cell phone than the alphanumeric touchscreen of a smartphone. Further, cell phones do not support apps, mobile telephone specific software common on smartphones. A researcher may need to provide a smartphone to a cell phone user for the purposes of data collection (e.g. as 
in Irvine et al., 2012). However, even where there is high smartphone penetration, a researcher seeking to use a particular app may still have difficulties depending on the type of application they wish to use.

Whilst SMS works across different mobile brands and phone platforms, apps commonly have compatibility with a particular operating system (e.g. Android or iOS). Though there is an impetus toward cross-brand app development (Ribeiro \& Da Silva, 2012), with some cross platform survey software (such as QuickTapSurvey; QuickTap Survey, 2014) the end user experience is often different due to differences in design and layout. Even with very similar mobile phones, people can have markedly different end user experiences in terms of ease of use and speed with which menu navigation can be achieved (Keijzers, Ouden, \& Lu, 2008). In terms of psychological research, studies on paper and online surveys note that response behaviour is modified by implicit visual layout cues (Dillman, Smyth, \& Christian, 2009; Smyth \& Dillman, 2006), which are to some degree dictated by the size of a device.

In self-report research, size does matter. In paper surveys, a smaller page size is associated with lower response rates than larger page counterparts (Jansen, 1985). For online instruments, compact question spacing can make instruments more difficult to read and engage with (Smith, 1993). The spacing of questions also impacts on response length. In paper and online surveys, larger response areas prompt longer responses than smaller response areas (Dillman et al., 2009), and shorter and more clearly delineated response areas beget more precise responses (Fuchs, 2009). Whilst it can be expected a cell phone screen will be small (typically under $7 \mathrm{~cm}$ across the diagonal), smartphone display sizes can differ drastically. There is also the mechanical difficulty of response composition. Aside from a general impact of mobile screen size on usability, with smaller screens being generally more difficult to use (Chae \& Kim, 2004), touch screen key size is significantly associated with the 
speed and accuracy of use (Park \& Han, 2010). The more difficult it is to type a response, the more burdensome responding becomes, and response burden is closely associated with response rates and attrition (Bolger, Davis, \& Rafaeli, 2003).

Providing participants with a mobile phone for the duration of data collection to standardize the response experience is not an entirely new phenomenon. However, the mobile phone ownership landscape has drastically changed in recent years, and there are to date no structured investigations of the ways in which lending participants a mobile telephone (rather than having them use their own phone) may impact upon their response behaviour. One major issue is that, with the majority of the global population actively using a mobile telephone, lending a mobile telephone to a participant will likely involve replacing one already in use (as was the case in Irvine et al., 2012).

In this scenario, using the provided mobile is a novel experience for the participant. In general, novelty motivates people to engage with an experience (Berlyne, 1950), and indeed, novel modes of participation can increase engagement with research (Dillman, 2009). In a review of email survey response rates over time, Sheehan (2006) posited that the trend of participants providing more detailed, lengthy responses when email was a relatively new technology, relative to later years when email was more established, was due to the novelty of the technology. It may be that providing participants with a novel mobile phone might impact on responses, perhaps encouraging longer and more detailed responses by engaging participants by way of novelty. However, providing a mobile telephone to a participant raises a consideration beyond the handset itself.

For some phones the telephone number, contacts, and other data is associated with the SIM card inside the handset. The researcher must consider whether they provide both the handset and SIM card, or whether the participant ought to transfer their own SIM card into 
the new handset. If a participant can use their own SIM card in the novel handset, their friends, family and colleagues can still contact the same number whilst they participate in the study. By retaining their own SIM, they can use the provided handset as they would their own mobile. Alternately, if a participant is provided with a SIM, the new handset is only useful for the purposes of participation. Because the researchers are liable for the credit on a provided SIM, they are likely to limit its capacity for non-research purposes lest participants accrue unreasonable bills. A provided SIM is therefore less useful to participants than their own SIM. As perceived usefulness is associated with technology acceptance and usage (Venkatesh, Thong, \& Xu, 2012), it is possible that previously established habits, including keeping a mobile nearby, will transfer to the new handset only if it is useful (i.e. has the participant's SIM). It may be that the low utility of a handset and SIM provided by the researcher could result in response delays, as the participant is more likely to forget the handset.

Usage habits of general functionality may also come in to play. It is likely that SMS is already part of a participant's daily life, given high rates of SMS usage in the general population (ACMA, 2011). This means participants have prior experience with SMS, and will find it useful beyond responses sent to the researcher. Conversely, participants are unlikely to have a history of everyday usage of the particular survey app chosen by the researcher, and by its nature, the app will only be useful for the purposes of research participation. For these reasons, it is possible that the impact of novelty and utility of the handset on participant behaviour will be different depending on whether participants respond via app, or SMS. These two response methods should therefore be considered separately.

This study investigates the impact of providing a mobile telephone to participants for the purposes of participating in research, comparing the response behaviour of participants using their own mobile against those using one provided by the researcher. Both app and SMS data collection methods will be used to collect self-report data on the standardized 
response platform of an iPhone. Because provision of a mobile handset may provide a novel participation experience and that novelty may increase engagement, we propose a novelty hypothesis, whereby providing a mobile telephone should be associated with more complete responses. Specifically, more questions will be attempted by participants using a borrowed mobile phone than those using their own mobile phone. As a participant's own mobile phone is already useful, and integrated into their daily life, we propose a utility hypothesis, predicting that participants using their own mobile telephone will provide quicker responses than those using a borrowed mobile. To account for possible differences due to the specific response method, these hypotheses will be investigated separately for people responding via app and SMS. As important drivers of how people engage with information flow (Marathe \& Sundar, 2011), the perceived privacy and convenience of participants using their own phone will be contrasted with those using a borrowed phone.

\section{Materials and Methods}

\subsection{Participants}

179 undergraduate students in Australia aged 17-55 (M=22), 58\% female, participated in return for course credit. All but one already owned a mobile telephone, $65 \%$ owned an iPhone.

\subsection{Materials}

An initial online questionnaire consisted of personal demographic (such as age and gender), and mobile ownership demographic questions. This was followed by repeated administrations of the same six-item questionnaire on the topic of mental time travel. Each question required a numeric or short open-ended response. The first five questions were specified as mandatory, while the sixth was optional. Those responding via app did so via iSurvey (iSurvey, 2014). 
Those responding via SMS replied using their own phone plans, or if using a SIM provided by the researcher, a pre-paid Lebara mobile plan. Participants borrowing a phone were given an iPhone 3 and charger for the duration of participation. A final exit questionnaire asked about participant's perceptions of privacy and convenience while participating in the repeated measures portion. In the interests of space and conceptual simplicity, and in recognition that a wider Likert range is only informative with a large sample (Peabody, 1962), the valance rather than extremity of opinion of privacy and convenience was measured on a scale of poor, neutral and good.

\subsection{Procedure}

Table 1

\section{Response conditions}

\begin{tabular}{|l|ll|}
\hline & Own SIM & Borrowed SIM \\
\hline Own mobile & Low novelty & \\
& High utility & \\
Borrowed mobile & High novelty & High novelty \\
& High utility $\quad$ Low utility \\
\hline
\end{tabular}

Participants were assigned to one of three conditions, described in Table 1. The decision to not utilise full random assignment was pragmatic. It is not possible to assign participants to owning or not owning an iPhone, and to give an iPhone owner another iPhone, or to give them a different SIM to put in their own phone would create bothersome logistical issues for the participants without guaranteeing improved data. Those who already owned an iPhone participated in the own SIM/own mobile condition. Those who did not own an iPhone were 
randomly assigned to either use own SIM/borrowed phone, or borrowed SIM/borrowed phone provided by the researchers. Due to a pragmatic element of a limited licensing timeframe for the iSurvey app, data collection began with all participants responding via app. Once the license expired, all subsequent participants responded via SMS. Upon signup, participants were not aware whether they would be responding via app or SMS, as the specific response mode was not mentioned in recruitment materials.

Participants met with the researcher for an initial meeting to complete online demographic surveys, and receive information regarding the repeated measures component. Those who did not own an iPhone were given an overview of how to operate the device, and were randomly assigned to the own-SIM/borrowed-SIM conditions. Participants responding via app were guided through process of app installation. All participants received a test prompt SMS, and made a practise attempt at the six-item questionnaire in the presence of the researcher to confirm correct contact details, and clarify the response process. Those responding via app had the six-item questionnaire pre-loaded, whilst those responding via SMS were sent the six-item questionnaire via SMS either during, or within 30 minutes of this meeting.

Participants received 20 SMS prompts on an individualised random schedule across two days (10 per day), prompting them to complete the six-item questionnaire. Those responding via SMS replied to the prompt with their answers, whilst those responding via app responded within iSurvey. Participants then attended a follow-up appointment, where they returned borrowed iPhones, uploaded results from the app, and completed an online questionnaire regarding their experiences of participation. Those in the SMS condition who were not on an unlimited plan were reimbursed for the cost of sending SMS associated with participation. 
Incoming SMS data was manually parsed by the researcher, and combined with app responses downloaded from the app's online database. For subsequent analysis, response behaviour was broadly operationalised in terms of completeness and promptness. As the focus here is how complete response attempts are, analyses are only for responses where the person responded to a prompt and answered at least one question. A response was considered partially complete if at least one question was complete, basically complete if all five mandatory questions were completed, and fully complete if all six questions (the sixth being specified as optional in instructions) were completed. Percentage completed was calculated as the number of questions attempted, relative to a basic completion, such that if five questions were attempted, completion was considered $100 \%$. To disentangle whether participants were responding as requested, or on their own schedule, responses were coded as to whether they were asked for (i.e. following a prompt), or extraneous (i.e. the preceding prompt had already received a response).

Response delay was operationalised as the number of minutes between a prompt, and the next response (in minutes). As is often the case in response time variables, response delay was bounded at one, as the shortest delay possible was coded as one minute, and significantly skewed. As this data shape was theoretically expected, the data was not transformed, but rather models were fit with a poisson distribution. Finally, to detect cutting and pasting rather than genuine response attempts, responses were screened for duplicates by calculating a similarity measure based on the Levenshtein edit distance (including capitalization) between each response and its immediate predecessor (within participants), with a distance of 1 indicating a duplicated response. To equate across different sample sizes across conditions, this was expressed as a percentage of total responses from that condition.

\subsection{Condition imbalance}


Analyses need to be considered in the context of the small sample size of participants in conditions where they respond via SMS using a borrowed phone. The initial recruitment plan, to have half of the participants using their own phone, and the other half borrowing, was hampered due to two factors. Firstly, upon signing up for the study, there were approximately half as many participants stating that they did not own an iPhone than those who did. This was then compounded by a disproportionate non-attendance rate of those who signed up on the understanding that they would borrow an iPhone, ultimately resulting in unbalanced, small cell sizes. As this pattern continued across two years of recruitment, it became clear that this was a persistent issue. Cook and Campbell (1979) note attrition at any point (even between recruitment and participation) can be informative. The initial difficulty in recruiting participants who did not own an iPhone is educative, as it suggests that, at least in an Australian university setting, a standardized response platform can be achieved without the need to lend mobile phones. To explore the disproportionately low attendance rate in those signed up to borrow iPhones, a follow-up questionnaire was distributed to all participants who did not attend their scheduled appointments. Participants were asked why they had not turned up to the appointment via multiple choice, tick-all-that-apply options (they forgot, attending was too inconvenient, or they decided to do another study), and open-ended response.

\subsection{Analyses and power}

This analysis consists of multilevel models, and contingency tables with $\chi^{2}$ tests. Multilevel models allow analysis of repeated measures nested within individuals, and then comparison between individuals, in a single model. This allows slopes, intercepts, and associated error to be apportioned in a way that accounts for the structure of the data. The concept of "power" in the classical sense is problematic in the current multilevel models; particularly as the current data is expected to involve logistic and non-normal distributions. Accordingly, predictor 
significance will be discussed in terms of $95 \%$ confidence intervals, bootstrapped at 500 replicates, constructed around model parameters. The power statistic reported alongside the $\chi^{2}$ tests were calculated using the "pwr" package for R (Champley, 2012), which essentially adjust Cramer's $\phi$, for sample size and number of cells involved in the contingency table.

\section{Results}

\subsection{Response behaviour}

Analysis consisted of a series of logistic multilevel models, with ownership as a predictor of receipt of each outcome variable, nested by participant at level 1 . The effect of using a borrowed mobile phone was examined in separate models for those responding via app, and those responding via SMS. The focus is not on the comparison between app and SMS, this division of data is to remove the potential confounding of response format on the relationship between novelty, utility and response behaviour. For participants who responded via app, models included comparison between those using their own mobile phone, and those using a borrowed mobile. For participants who responded via SMS, models included comparisons between three groups: own mobile, borrowed mobile / own SIM, and borrowed / borrowed SIM. The descriptive statistics of the outcome variables, by condition, are presented in Table

2. A summary of the model coefficients, and confidence intervals, are reported in Table 3. 
Table 2

Response completeness and delay summary

\begin{tabular}{|c|c|c|c|c|c|c|c|c|c|}
\hline & & & & & & & $\%$ & Median & \\
\hline & & & M \% & & & & extraneous & response & duplicate \\
\hline & & $\mathrm{n}$ & complete & & omplet & & responses & delay & responses \\
\hline & & & & Partial & Basic & Full & & & \\
\hline$\overline{A p p}$ & Borrowed & 39 & $83 \%$ & $82 \%$ & $75 \%$ & $99 \%$ & $12.20 \%$ & $7 \mathrm{~min}$. & $1 \%$ \\
\hline & Own & 54 & $75 \%$ & $74 \%$ & $61 \%$ & $98 \%$ & $2.63 \%$ & $3 \mathrm{~min}$. & $<1 \%$ \\
\hline SMS & & & & & & & & & \\
\hline (borr & & & & & & & & & \\
\hline wed & & & & & & & & & \\
\hline SIM) & Borrowed & 13 & $59 \%$ & $24 \%$ & $23 \%$ & $82 \%$ & $12 \%$ & $7.5 \mathrm{~min}$. & 0 \\
\hline (own & & & & & & & & & \\
\hline SIM) & Borrowed & 11 & $75 \%$ & $36 \%$ & $36 \%$ & $88 \%$ & $3 \%$ & $5 \mathrm{~min}$. & $<1 \%$ \\
\hline & Own & 62 & $74 \%$ & $33 \%$ & $29 \%$ & $86 \%$ & $4 \%$ & $4 \mathrm{~min}$. & $2 \%$ \\
\hline
\end{tabular}

Note. $\mathrm{M}=$ mean, $\mathrm{n}=$ sample size. 
Table 3

Multilevel model intercept and coefficients for models investigating the relationship between mobile ownership and response properties.

App

SMS

\section{Partial response rate}

Level $2 \quad b(S D)=2.17,[1.94,3.28]^{*}$

$\mathrm{b}(\mathrm{SD})=1.50,[1.38,2.15]^{*}$

Level 1

$\mathrm{b}=-0.78,[-0.95,-1.98]^{*}$

Own mobile

$\mathrm{b}=0.82,[-0.002,1.63]$

Borrowed mobile $\quad b=1.01,[-0.23,2.38]$

\begin{tabular}{|c|c|c|c|}
\hline & Basic response rate & & \\
\hline Level 2 & $\mathrm{~b}(\mathrm{SD})=2.05,[1.82,3.04]^{*}$ & & $\mathrm{~b}(\mathrm{SD})=3.33,[3.12,4.70]$ \\
\hline \multirow[t]{3}{*}{ Level 1} & $b=-0.73,[-1.79,0.03]$ & Own mobile & $\mathrm{b}=1.00,[-1.01,4.20]$ \\
\hline & & Borrowed mobile & $b=0.96,[-2.61,4.56]$ \\
\hline & Full response rate & & \\
\hline Level 2 & $b(S D)=2.11,[1.92,2.87]^{*}$ & & $b(S D)=3.17,[2.97,4.45]^{*}$ \\
\hline \multirow[t]{2}{*}{ Level 1} & $b=-1.10,[-2.21,-0.41]^{*}$ & Own mobile & $b=0.72,[-1.26,3.72]$ \\
\hline & & Borrowed mobile & $\mathrm{b}=1.008,[-2.35,4.39]$ \\
\hline
\end{tabular}

\section{Extraneous responses}

Level $2 \quad b(S D)=1.47,[1.71,3.34]^{*}$

Level $1 \quad b=-1.45,[-2.79,-0.79]^{*}$

\section{Duplicate responses}

Level $2 \quad b(S D)=1.13,[2.59,7.44]^{*}$

Level $1 \quad b=-0.27,[-1.67,1.24]$

Response delay

Level $2 \quad b(S D)=0.91,[0.84,1.07]^{*}$

$\mathrm{b}(\mathrm{SD})=.866,[.814,1.04]^{*}$

Level 1

$\mathrm{b}=-0.38,[-0.40,-0.05]^{*}$

Own mobile

$\mathrm{b}=-.946,[-946, .137]$

Borrowed mobile $\quad b=-.575,[-1.202,0.105]$

Note. Data from those responding via app, and SMS, are modelled separately. Base group for comparison in App models is own mobile, and the base group in SMS models is borrowed mobile/borrowed SIM. * indicates significance, denoted by $95 \%$ confidence intervals (in square brackets) not including zero. 
Consistently significant level 2 intercepts across models indicate nesting by participant is meaningful for this data. There was no significant difference in partial or basic response rate between those using their own, or a borrowed, mobile phone (Table 3). There was a significant difference in the full response rate in those responding via app, but not those responding via SMS. Taking the exponent of the significant coefficient gives an odds ratio of 0.33 , that is, participants using their own mobile were significantly and moderately less likely to provide a full response than those using a borrowed mobile.

Amongst those responding via app, mobile ownership was significantly associated with extraneous responses. Taking the exponent of the significant coefficient gives an odds ratio of 0.23 , that is, participants using their own mobile were significantly and moderately less likely to provide an extraneous response than those using a borrowed mobile. Mobile ownership was not significantly associated with duplicate responses. Amongst those responding via SMS, there were too few extraneous and duplicate responses for statistical analysis.

Mobile ownership significantly impacted on response delay in those responding via app, but not those responding via SMS. Specifically, those using their own mobile responded significantly more quickly than those using a borrowed mobile.

\subsection{Participant perceptions}

Six chi-square tests were completed to explore the differences in participant perceptions of convenience and privacy, based on whether they used their own mobile, or one provided by researchers, and their own or a borrowed SIM. Count data is summarised in Table 4. Power was calculated as per Champely (2012), and is reported alongside Fishers's exact $\rho$. 
Table 4

Counts of ratings of participation experience.

\begin{tabular}{|c|c|c|c|c|c|c|c|}
\hline \multirow[b]{2}{*}{ Mode } & \multirow[b]{2}{*}{ Ownership } & \multicolumn{3}{|c|}{ Convenience } & \multicolumn{3}{|c|}{ Privacy } \\
\hline & & Poor & Neutral & Good & Poor & Neutral & Good \\
\hline & & 1 & 8 & 43 & 0 & 7 & 46 \\
\hline \multirow[t]{4}{*}{ App } & Own & $(1 \%)$ & $(15 \%)$ & $(84 \%)$ & $(0 \%)$ & $(13 \%)$ & $(87 \%)$ \\
\hline & & 1 & 11 & 24 & 0 & 11 & 25 \\
\hline & Borrowed & $(1 \%)$ & $(31 \%)$ & $(68 \%)$ & $(0 \%)$ & $(31 \%)$ & $(69 \%)$ \\
\hline & & 4 & 18 & 36 & 2 & 11 & 43 \\
\hline \multirow[t]{5}{*}{ SMS } & Own & $(6 \%)$ & $(32 \%)$ & $(62 \%)$ & $(4 \%)$ & $(20 \%)$ & $(76 \%)$ \\
\hline & & 1 & 2 & 9 & 0 & 3 & 9 \\
\hline & Borrowed (own SIM) & $(9 \%)$ & $(16 \%)$ & $(75 \%)$ & $(0 \%)$ & $(25 \%)$ & $(75 \%)$ \\
\hline & & 0 & 1 & 8 & 0 & 3 & 6 \\
\hline & Borrowed SIM (borrowed SIM) & $(0 \%)$ & $(12 \%)$ & $(88 \%)$ & $(0 \%)$ & $(25 \%)$ & $(75 \%)$ \\
\hline
\end{tabular}

Amongst participants responding via app, there were no significant differences in ratings of convenience or privacy $\left(\chi^{2}=3.05, p=.205\right.$, power $=.326, \rho=.169$ and $\chi^{2}=3.99$, $p=.067$, power $=.516, \rho=.061$ respectively) between those using their own mobile telephones, and those using mobile phones provided by the researcher. Interpretation of perceptions of convenience and privacy is undermined by the small and unequal cell sizes in the SMS responses, resulting in low analytical power. There did not appear to be any significant differences in perceptions of convenience or privacy $\left(\chi^{2}=1, p=.769\right.$, power=.133, $\rho=.585$ and $\chi^{2}=.57, p=1$, power $=.09, \rho=.803$ respectively) between those responding via SMS using their 
own or a borrowed iPhone. Neither were there any significant differences in terms of convenience or privacy $\left(\chi^{2}=.983, p=1\right.$, power $=.131, \rho=1$ and $\chi^{2}=.175, p=1$, power $=.07, \rho=1$ respectively) between those using a borrowed iPhone with their own SIM or one provided. Together, these analyses tentatively indicate that participant perceptions regarding participation convenience and privacy generally do not differ depending on whether they are using their own, or a borrowed, mobile.

\subsection{Condition imbalance}

Given that the sampling frame was non-respondents in the main study, the response rate was understandably low ( $n=17)$. With ages ranging from 18 to $53(\mathrm{M}=27)$ years, $41 \%$ of the respondents to the follow-up questionnaire were male. Six owned an iPhone, nine a different brand of smartphone, and two something other than a smartphone. Fifty eight percent forgot, $23 \%$ reported the appointment time was inconvenient, and $17 \%$ decided to do a different study. Reasons specific to borrowing an iPhone had significantly less endorsement, with only two people agreeing they were worried they'd break the iPhone, and one person not wanting the hassle of returning the iPhone.

\section{Discussion}

Response behaviour was influenced by whether participants used their own mobile, or a borrowed mobile telephone for participation. The novelty hypothesis, that participants using a borrowed phone would engage more with the research and thus provide more complete data, was supported amongst those responding via app, but not those responding via SMS. App respondents using a borrowed phone were more likely to go beyond the basic response requirements, providing significantly more full and extraneous responses than those using 
their own mobile. The lack of support for the hypotheses in the SMS respondents may be a result of the lower SMS response rate we found, meaning that there were fewer responses in total to differentiate between partial, basic and full responses. Alternately, it may be because all participants were familiar with SMS, so using SMS on an unfamiliar device was a less novel experience than using an unfamiliar app on an unfamiliar device. This second interpretation is supported by the significant interaction between whether participants responded via SMS or app, and using their own or a borrowed phone.

The utility hypothesis, suggesting that participants using their own mobile telephone should provide significantly quicker responses, was supported in those responding via app, but not those responding via SMS. However, unless the researcher is very concerned with response promptness, the statistical significance may not be practically meaningful, with the median response delay between groups being less than five minutes. The generally short response delays were consistent with participants keeping the borrowed phone with them, and being relatively vigilant for incoming prompts, rather than leaving the phone at home and forgetting to check them. Needing to keep the phone with them did not appear to be particularly burdensome, as across all groups, participants generally rated the convenience of participation as 'good'.

Participants using a borrowed SIM and handset, who likely had to keep both the researcher's and their own mobile with them, did not significantly differ from the other groups in terms of perceived convenience. Perceptions of privacy were unaffected by whether participants were using their own, or a borrowed mobile phone. This finding may have limited generalizability to the broader population, due to low statistical power, and due to the younger age of the sample. Younger adults tend to be less conscious of the privacy considerations of mobile telephone use than older adults (Ling, 2008). 
At the time of data collection, iPhones were the dominant smartphone in Australia (representing 53\% of smartphone sales; ACMA, 2012). One factor contributing to the difficulty in recruiting non-iPhone owners is therefore that a large portion of the undergraduate population the sample was drawn from likely already owned an iPhone. The disproportionate number of no-shows in those signed up to borrow a mobile phone was not explained by follow-up queries, with no indication of concerns specific to borrowing an iPhone reported. The technology acceptance model (Venkatesh, Thong, \& Xu, 2012) notes that perceptions of usefulness are an important factor in technology uptake. It may be that potential participants who already have a mobile perceive the act of borrowing a mobile as not useful, reducing the behavioural intention to participate.

While undergraduates are a frequently used population in research, children are becoming the most common group being provided with mobile telephones for the purposes of participation. Research on adults is not directly applicable, as children engage with their mobile telephones in a distinct way (Lorente, 2002), tending to experiment more with the full capabilities of a phone rather than using just a few services (Inyang et al., 2010). Just as in the adult population, mobile ownership is becoming increasingly common in children (Davie, Panting, \& Charlton, 2004), so the same issues associated with replacing a mobile phone already in use in the interests of standardization may well apply. Researchers working with children have a particular reason to consider providing a SIM card for participation (as in Shapiro et al., 2008); a child's SIM provides a direct method of contact that bypasses parental monitoring and control, and many parents may be concerned about providing their child's direct contact details to the researcher. Dunton, Liao, Intille, Spruijt-Metz and Pentz (2011) suggest providing a SIM to be used in the child's own mobile handset for the purposes of research only. Future research focussing on the effect of lending a mobile on the response behaviour of children should consider adding this condition to the design of the current study. 
It should be noted that, for practical reasons, this study did not randomly assign who used their own, and who used a borrowed mobile telephone. It is possible that the differences between the own and borrowed conditions are related to characteristics of people who choose to own an iPhone versus those who do not. If this is the case, generalizability is limited to research situations where an iPhone is chosen as a standard platform. This possibility could be investigated in future research by assigning a different standard (such as an Android smartphone).

\section{Conclusions}

This study investigated the impact of providing a mobile telephone to participants for the purposes of participating in research. Results indicate that researchers seeking to conduct self-report research using mobile phones should be aware that the choice to provide a mobile telephone to standardise participant response platforms can be related to differential response behaviour. Lending a smartphone is costly in terms of initial outlay, and requires a physical meeting with participants to provide the phone, and regardless of the cause of the difficulty in recruiting participants when pre-existing phones are to be replaced for the purposes of participation further discourages lending phones. Given that providing a mobile phone or SIM had no significant effects on response behaviour, a researcher seeking to use SMS may consider abandoning standardisation in preference for maximising recruitment by allowing participants to use their own mobile phones. However, if the researcher seeks to use an app, standardisation of mobile telephones may be unavoidable, and can benefit data quality in terms of data completeness and response promptness. 


\section{References}

ACMA. 2011. ACMA Communications report 2010-2011.

ACMA. 2012. Communications report Report 3 - Smartphones and tablets Take-up and use in Australia Summary report.

Aggarwal, N. K. 2012. Applying mobile technologies to mental health service delivery in South Asia. Asian journal of psychiatry, 5(3), 225-30. doi:10.1016/j.ajp.2011.12.009

Alfven, G. 2010. SMS Pain Diary: A Method for Real Time Data Capture of Recurrent Pain in Childhood. Acta Paediatricia, 99(7), 1047 - 1053. doi:10.1111/j.1651-2227.2010.01735.x

Andreatta, P., Debpuur, D., Danquah, A., \& Perosky, J. 2011. Using cell phones to collect postpartum hemorrhage outcome data in rural Ghana. International journal of gynaecology and obstetrics, 113(2), 148-51. doi:10.1016/j.ijgo.2010.11.020

Axén, I., Bergström, G., \& Bodin, L. 2013. Using few and scattered time points for analysis of a variable course of pain can be misleading: an example using weekly text message data. The spine journal. doi:10.1016/j.spinee.2013.08.035

Bauer, S., De Niet, J., Timman, R., \& Kordy, H. 2010. Enhancement of care through self-monitoring and tailored feedback via text messaging and their use in the treatment of childhood overweight. Patient education and counseling, 79(3), 315-9. doi:10.1016/j.pec.2010.03.014

Berkman, E. T., Dickenson, J., Falk, E. B., \& Lieberman, M. D. 2011. Using SMS Text Messaging to Assess Moderators of Smoking Reduction : Validating a New Tool for Ecological Measurement of Health Behaviors. Health Psychology, 30(2), 186-194. doi:10.1037/a0022201

Berlyne, D. E. 1950. Novelty and curiosity as determinants of exploratory behavior. Journal of psychology, 41(1), 68-69. doi:j.2044-8295.1950.tb00262.x

Bexelius, C., Merk, H., Sandin, S., Ekman, A., Nyrén, O., Kühlmann-Berenzon, S., Linde, A., et al. 2009. SMS versus telephone interviews for epidemiological data collection: feasibility study estimating influenza vaccination coverage in the Swedish population. European journal of epidemiology, 24(2), 73-81. doi:10.1007/s 10654-008-9306-7

Bolger, N., Davis, A., \& Rafaeli, E. 2003. Diary methods: Capturing life as it is lived. Annual review of psychology, 54(1), 579-616. doi:10.1146/annurev.psych.54.101601.145030

Boulos, M. N. K., Brewer, A. C., Karimkhani, C., Buller, D. B., \& Dellavalle, R. P. 2014. Mobile medical and health apps: state of the art, concerns, regulatory control and certification. Online journal of public health informatics, 5(3), 229. doi:10.5210/ojphi.v5i3.4814

Broderick, C. R., Herbert, R. D., Latimer, J., Mathieu, E., Van Doorn, N., \& Curtin, J. a. 2012. Feasibility of short message service to document bleeding episodes in children with haemophilia. Haemophilia, 18(6), 906-10. doi:10.1111/j.1365-2516.2012.02869.x

Champely, S. 2012. pwr: Basic functions for power analysis. R package version 1.1.1., available at http://CRAN.R-project.org/package=pwr

Chae, M., \& Kim, J. 2004. Do size and structure matter to mobile users? An empirical study of the effects of screen size, information structure, and task complexity on user activities with standard web phones. Behaviour \& Information Technology, 23(3), 165-181. doi:10.1080/01449290410001669923

Chen, Y., Chin, M., Greenberg, S., Johnstone, C., \& McGuinness, J. 2012. Post-tonsillectomy pain in 24 children - utilising short message service (SMS) to assess postoperative outcomes. Clinical otolaryngology, 37(5), 412-4. doi:10.1111/j.1749-4486.2012.02521.x

Chib, A., Wilkin, H., Ling, L. X., Hoefman, B., \& Van Biejma, H. 2012. You have an important message! Evaluating the effectiveness of a text message HIV/AIDS campaign in Northwest Uganda. Journal of health communication, 17(1), 146-57. doi:10.1080/10810730.2011.649104

Cook, T. D., \& Campbell, D. T. 1979. Quasi-Experimentation Design and Analysis issues for Field Settings (pp. 37 - 95). Boston: Houghton Mifflin Company.

Davie, R., Panting, C., \& Charlton, T. 2004. Mobile phone ownership and usage among pre-adolescents. Telematics and Informatics, 21(4), 359-373. doi:10.1016/j.tele.2004.04.001

De Niet, J., Timman, R., Bauer, S., Van den Akker, E., De Klerk, C., Kordy, H., \& Passchier, J. 2012. Short message service reduces dropout in childhood obesity treatment: a randomized controlled trial. Health psychology, 31(6), 797-805. doi:10.1037/a0027498

Devine, S., Ph, D., Bull, S., H, M. P., Dreisbach, S., \& Shlay, J. 2014. Enhancing a Teen Pregnancy Prevention Program With Text Messaging : Engaging Minority Youth to Develop TOP Plus Text. Journal of Adolescent Health, 54(3), S78-S83. doi:10.1016/j.jadohealth.2013.12.005

Dillman, D. A., Smyth, J. D., \& Christian, L. M. 2009. Internet, Mail, and Mixed-Mode Surveys (Third.). New Jersey: John Wiley \& Sons. 
Dunton, G. F., Liao, Y., Intille, S. S., Spruijt-Metz, D., \& Pentz, M. 2011. Investigating children's physical activity and sedentary behavior using ecological momentary assessment with mobile phones. Obesity, 19(6), 1205-12. doi:10.1038/oby.2010.302

Fuchs, M. 2009. Differences in the Visual Design Language of Paper-and-Pencil Surveys Versus Web Surveys: A Field Experimental Study on the Length of Response Fields in Open-Ended Frequency Questions. Social Science Computer Review, 27(2), 213-227. doi:10.1177/0894439308325201

Gold, J., Aitken, C. K., Dixon, H. G., Lim, M. S. C., Gouillou, M., Spelman, T., Wakefield, M., et al. 2011. A randomised controlled trial using mobile advertising to promote safer sex and sun safety to young people. Health education research, 26(5), 782-94. doi:10.1093/her/cyr020

Inyang, I., Benke, G., Dimitriadis, C., Simpson, P., McKenzie, R., \& Abramson, M. 2010. Predictors of mobile telephone use and exposure analysis in Australian adolescents. Journal of paediatrics and child health, 46(5), 226-33. doi:10.1111/j.1440-1754.2009.01675.x

Irvine, L., Falconer, D. W., Jones, C., Ricketts, I. W., Williams, B., \& Crombie, I. K. 2012. Can text messages reach the parts other process measures cannot reach: an evaluation of a behavior change intervention delivered by mobile phone? PloS one, 7(12), e52621. doi:10.1371/journal.pone.0052621

iSurvey (n.d.). Retrieved August 20, 2014, from https://itunes.apple.com/au/app/isurvey-offline-surveys-data/id341427957?mt=8

International Telecommunication Union (2014) The World in 2014: ICT facts and figures. Retrieved December 2014, https://www.itu.int/en/ITU-D/Statistics/.../ICTFactsFigures2014-e.pdf

Jansen, J. 1985. Effect of questionnaire layout and size and issue-involvement on response rates in mail surveys. Perceptual and Motor Skills, 139-142. doi:pdf/10.2466/pms.1985.61.1.139

Joe, J., \& Demiris, G. 2013. Older adults and mobile phones for health: a review. Journal of biomedical informatics, 46(5), 947-54. doi:10.1016/j.jbi.2013.06.008

Kazi, A. M., Murtaza, A., Khoja, S., \& Ali, S. A. 2014. Lessons from the field Monitoring polio supplementary immunization activities using an automated short text messaging system in Karachi, Pakistan. Bull World Health Organ, 92, 220-225. doi:http://dx.doi.org/10.2471/BLT.13.122564

Keijzers, J., Ouden, E. Den, \& Lu, Y. 2008. Usability benchmark study of commercially available smart phones: cell phone type platform, PDA type platform and PC type platform. Human computer interaction with mobile devices, 265-272. Retrieved from http://dl.acm.org/citation.cfm?id=1409269

Kuntsche, E., \& Labhart, F. 2013. Using Personal Cell Phones for Ecological Momentary Assessment. European Psychologist, 18(1), 3-11. doi:10.1027/1016-9040/a000127

Lagerros, Y. T., Sandin, S., Bexelius, C., Litton, J.-E., \& Löf, M. 2012. Estimating physical activity using a cell phone questionnaire sent by means of short message service (SMS): a randomized population-based study. European journal of epidemiology, 27(7), 561-6. doi:10.1007/s10654-012-9708-4

Lim, M. S. C., Sacks-Davis, R., Aitken, C. K., Hocking, J. S., \& Hellard, M. E. 2010. Randomised Controlled Trial of Paper, Online and SMS Diaries for Collecting Sexual Behavior Information from Young People. Journal of Epidemiology and Community Health, 64(10), 885-889. doi:10.1136/jech.2008.085316

Ling, R. 2008. Should We Be Concerned That the Elderly Don't Text? The Information Society, 24(5), 334-341. doi: $10.1080 / 01972240802356125$

Lorente, S. 2002. Youth and mobile telephones: more than a fashion. In E. A. Villar (Ed.), Revista de Estudios de Juventud (pp. 9-24).

Lori, J. R., Munro, M. L., Boyd, C. J., \& Andreatta, P. 2012. Cell phones to collect pregnancy data from remote areas in Liberia. Journal of nursing scholarship, 44(3), 294-301. doi:10.1111/j.1547-5069.2012.01451.x

Macedo, L. G., Maher, C. G., Latimer, J., \& McAuley, J. H. 2012. Feasibility of using short message service to collect pain outcomes in a low back pain clinical trial. Spine, 37(13), 1151-5. doi:10.1097/BRS.0b013e3182422df0

Marathe, S., \& Sundar, S. S. 2011. What drives customization?: control or identity?. In Proceedings of the SIGCHI Conference on Human Factors in Computing Systems (pp. 781-790). ACM.

Mars, M. 2013. Telemedicine and Advances in Urban and Rural Healthcare Delivery in Africa. Progress in Cardiovascular Diseases, 56(3), 326-335. doi:10.1016/j.pcad.2013.10.006

Peabody, D. 1962. Two components in bipolar scales: Direction and extremeness. Psychological Review, 69(2), 65.

Park, Y. S., \& Han, S. H. 2010. Touch key design for one-handed thumb interaction with a mobile phone: Effects of touch key size and touch key location. International Journal of Industrial Ergonomics, 40(1), 68-76. doi:10.1016/j.ergon.2009.08.002

Proudfoot, J. 2013. The future is in our hands: the role of mobile phones in the prevention and management of mental disorders. The Australian and New Zealand journal of psychiatry, 47(2), 111-3. doi:10.1177/0004867412471441

Quick TapSurvey (n.d.). Retrieved August 20, 2014, from http://www.quicktapsurvey.com 
Ribeiro, A., \& Da Silva, A. R. 2012. Survey on Cross-Platforms and Languages for Mobile Apps. 2012 Eighth International Conference on the Quality of Information and Communications Technology (pp. 255-260). Ieee. doi:10.1109/QUATIC.2012.56

Shapiro, J. R., Bauer, S., Hamer, R. M., Kordy, H., Ward, D., \& Bulik, C. M. 2008. Use of text messaging for monitoring sugar-sweetened beverages, physical activity, and screen time in children: a pilot study. Journal of nutrition education and behavior, 40(6), 385-91. doi:10.1016/j.jneb.2007.09.014

Sheehan, K. B. 2006. E-mail Survey Response Rates: A Review. Journal of Computer-Mediated Communication, 6(2). doi:10.1111/j.1083-6101.2001.tb00117.x

Shingleton, R. M., Richards, L. K., \& Thompson-Brenner, H. 2013. Using technology within the treatment of eating disorders: a clinical practice review. Psychotherapy, 50(4), 576-82. doi:10.1037/a0031815

Smith, T. W. 1995. Little things matter: A sampler of how differences in questionnaire format can affect survey responses. In Proceedings of the American Statistical Association, Survey Research Methods Section (pp. 1046-1051). Alexandria VA: American Statistical Association.

Smyth, J., \& Dillman, D. 2006. Effects of using visual design principles to group response options in web surveys. International journal of internet science, 1(1), 6-16.

Suffoletto, B., Kristan, J., Callaway, C., Kraemer, K., \& Clark, D. 2011. Patterns of Alcohol Consumption in Young Adults Using Text-Message, AUDIT-C and Timeline Follow-Back Assessments. Annals of Emergency Medicine, 58(4), S199-S200. doi:10.1016/j.annemergmed.2011.06.093

ThinkInsights (2014) Australian Smartphone penetration. Retrieved December 2014, https://www.google.com.au/think/statistics/australian-smartphone-penetration.html

Venkatesh, V., Thong, J. Y. L., \& Xu, X. (2012). Consumer acceptance and use of information technology: extending the unified theory of acceptance and use of technology. MIS Quarterly, 1(2012), 1-43. 